\title{
SLOW AND FAST OPTICAL DEGRADATION OF THE SESAM FOR FIBER LASER MODE-LOCKING AT $1 \mu \mathrm{m}$
}

\author{
K. Viskontas ${ }^{\mathrm{a}, \mathrm{b}}$, K. Regelskis ${ }^{\mathrm{a}, \mathrm{b}}$, and N. Rusteika ${ }^{\mathrm{a}, \mathrm{b}}$ \\ ${ }^{a}$ Center for Physical Sciences and Technology, Savanoriu 231, LT-02300 Vilnius, Lithuania \\ ${ }^{\mathrm{b}}$ Ekspla UAB, Savanoriu 231, LT-02300 Vilnius, Lithuania \\ E-mail: karolis.viskontas@ar.fi.lt
}

Received 17 April 2014; accepted 29 May 2014

\begin{abstract}
In this paper, we introduce a detailed study of degradation of the $\operatorname{In}_{x} \mathrm{Ga}_{1-x}$ As quantum well $(\mathrm{QW})$ based semiconductor saturable absorber mirror (SESAM) irradiated with picosecond pulses from a fiber laser at a $1064 \mathrm{~nm}$ wavelength. In a slow degradation study at a lower incident fluence, the longest operating times of $\sim 4000 \mathrm{~h}$ were recorded for two SESAMs with a slow carrier relaxation $(\tau=15 \mathrm{ps})$ in comparison to $1000 \mathrm{~h}$ of the fast $(\tau=1 \mathrm{ps})$ SESAM. The nonlinear reflectivity measurements after the long-term tests indicated that the most likely mechanism of SESAM degradation was the modification of the InGaAs QW structure. By reducing a thermal load on the SESAM, an expected lifetime was increased ten-fold. At higher saturation levels, SESAMs experienced critical optical damage (COD) after less than $24 \mathrm{~h}$ of operation. The most likely mechanism of COD was deduced to be the two-photon absorption in GaAs material. The necessity of slow degradation tests close to the operating conditions of the SESAM was demonstrated.
\end{abstract}

Keywords: saturable absorber, SESAM, mode-locked fiber laser, optical degradation, Yb-doped fiber, ultrashort pulse PACS: $42.81 . \mathrm{Wg}, 42.65 . \mathrm{Re}, 42.70 . \mathrm{Ng}$

\section{Introduction}

Since its invention, the ultrashort pulse laser is an important research tool adapted in many scientific laboratories. It opened new fields of research such as femtochemistry [1], time-resolved [2] and terahertz spectroscopy [3], two-photon microscopy [⿰亻也 , optical comb metrology [4], etc. Ultrashort pulses can easily reach high peak intensities and with a high repetition rate are a promising tool for precise material processing $[5,6]$.

Generally, solid-state (bulk) mode-locked lasers, notably Ti:Sapphire lasers, are presently most commonly used in scientific research laboratories, but being bulky and expensive they have a limited application area in industry. Due to the development of optical communication industry, especially in optical fibers and semiconductor laser diode technologies, fiber lasers began to expand into the field of ultrashort pulse lasers. These lasers have a number of desired qualities: ultrafast fiber lasers can be made environmentally stable, maintenance-free, low-cost, and compact in size 沟. Moreover, a small quantum defect in the Yb-doped fiber leads to high power efficiencies and reduced thermal effects in the higher output power lasers [8].
Ultrashort optical pulses can be generated by locking phases of many longitudinal modes of the laser [9]. Although there are active mode-locking techniques [10], the absolute majority of commercial lasers are built using the passive mode-locking. There are several types of passive mode-locking available for fiber lasers. One is utilizing a nonlinear loop mirror as an artificial saturable absorber working on the Kerr effect [4]. Another is based on a nonlinear polarization rotation by the nonlinear Kerr effect in an optical fiber: the intensity-dependant change of the polarization state combined with the intra-cavity polarizer acts as an artificial saturable absorber [11]. The fiber laser mode-locking techniques based on the Kerr effect are widely used in scientific laboratories [12], but have some major shortcomings. Firstly, the Kerr mode-locking is usually realised in fibers without birefringence and therefore is susceptible to environmental changes (temperature, mechanical tension). Secondly, it is difficult to achieve a reliable self-starting mode-locking and often an additional starting mechanism is required [13]. The reliable selfstarting mode-locking can be achieved by introducing a material-based saturable absorber 帄. There are a lot of different highly nonlinear materials suitable for mode-locking [4]. Semiconductor saturable 
absorber mirrors (SESAMs) are widely used in ultrashort pulse lasers. By controlling the growth parameters of the semiconductor material and properly choosing the cavity design it is possible to tune all the relevant parameters (e. g. recovery time, saturation fluence, modulation depth, absorption wavelength) of a SESAM [14]. Although there are a lot of promising new nano-materials with good nonlinear optical properties (e. g. carbon nanotubes [15] and graphene [1]]), a lot of work should be done to fabricate reliable and reproducible mode-lockers of this type.

For operational wavelength of the Yb-doped fiber lasers (typically 1000-1100 nm), a SESAM based on the $\mathrm{In}_{x} \mathrm{Ga}_{1-x} \mathrm{As} / \mathrm{GaAs}$ super-lattice saturable absorber and AlAs/GaAs Bragg mirror is a common choice. It should be noted that there are some differences between SESAMs suitable for fiber lasers and SESAMs suitable for solid-state lasers [ [D. Specifically, the modulation depth of the absorber has to be much higher for fiber lasers to ensure their stable operation with a strong optical gain and large resonator losses. A higher modulation depth is usually achieved by increasing the number of InGaAs quantum wells. However, this leads to excessive mechanical strain within the device, as the absorber layers are often not exactly lattice-matched to the Bragg mirror structure [17] and can make the SESAM more susceptible to optical damage or faster degradation. The lifetime of a SESAM is a very important parameter to predict reliability of any mode-locked laser and can be defined as the time interval over which the nonlinear parameters of the device drop below a threshold required for stable mode-locking of a fiber laser. Although SESAMs have been used for about 20 years, to our knowledge, there are no direct longterm $(>1000 \mathrm{~h})$ studies about gradual degradation of such devices. Also, there are no systematic studies of any kind of degradation or damage of SESAMs designed for ultrafast fiber lasers. The fast damage studies were performed recently with prediction of the lifetime for SESAMs with a small modulation depth for solid-state lasers [18]. In this work, we set to investigate the slow and fast optical degradation and reliability of SESAMs suitable for the mode-locking fiber lasers at $1 \mu \mathrm{m}$ and if possible to find a protocol for the accelerated lifetime tests.

\section{Methodology}

In this study, different commercially available SESAMs produced by BATOP were investigated. Figure 11 represents a schematic view of the cross section of a typical SESAM structure. Multiple InGaAs quantum wells (QWs) were grown by molecular beam epitaxy on the top of the AlAs/GaAs Bragg mirror with a GaAs spacer

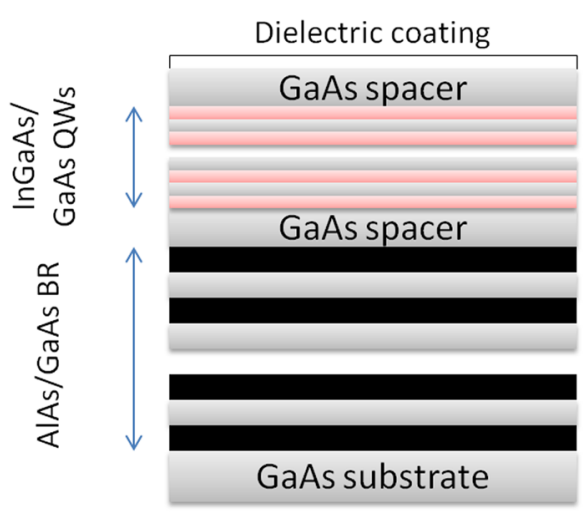

Fig. 1. Typical structure of InGaAs/GaAs SESAM for fiber lasers: (from top to bottom) dielectric coating, GaAs spacer, InGaAs QWs ( 10 nm single well, total number $\sim 10-20$ ), Bragg reflector (BR) composed of AlAs/GaAs multilayer containing $\sim 15-25$ periods, and GaAs substrate on which all the structure is grown.

in between. The Bragg mirror ensures high reflectivity of the SESAM over a large operational bandwidth. Absorption of the light pulses takes place in InGaAs QWs. The ratio of In and Ga in InGaAs QWs is fine-tuned to optimize the band-gap of the material for nonlinear properties. Fast (1-15 ps) carrier recovery time was achieved by growing InGaAs QWs at lower than standard temperatures and creating a large number of recombination defects. SESAMs were later annealed to stabilize the defects and coated with the dielectric top layer.

For the use in fiber lasers, SESAM chips with the size of $1.3 \times 1.3 \times 0.4 \mathrm{~mm}^{3}$ were butt-coupled to the ferule of the standard fiber connector on physical contact $(\mathrm{FC} / \mathrm{PC})$ containing a polarization-maintaining single-mode optical fiber (PM980). After ensuring a good mechanical and optical contact, the edge of a chip was glued to the ferule with cyanoacrylate glue. After fabrication, a pigtail of the SESAM could be fusion spliced to the rest of the fiber laser. For the fast degradation measurements, the glue was not applied to allow re-using the same chip for several times by selecting different spots on the chip. The contact between the SESAM and the ferrule was mechanically maintained in this case.

For a flat-top-shaped beam profile, the nonlinear reflectivity of the SESAM can be approximated by [18]:

$$
R\left(F_{\mathrm{p}}\right)=1-A_{\mathrm{ns}}-\Delta R \frac{1-\mathrm{e}^{\left(-F_{\mathrm{p}} / F_{\mathrm{sat}}\right)}}{F_{\mathrm{p}} / F_{\mathrm{sat}}}-F_{\mathrm{p}} / F_{\text {ISA }},
$$

where $F_{\text {sat }}$ is the saturation fluence, $F_{\mathrm{p}}$ is the incident fluence, $\Delta R$ is the modulation depth, $A_{\mathrm{ns}}$ is the nonsaturable loss, $F_{\mathrm{ISA}}$ is the coefficient of inverse saturable 
absorption (ISA). For the Gaussian-shaped beam, the incident fluence can be calculated as

$$
F_{\mathrm{p}}=\frac{E_{\mathrm{p}}}{A_{\text {eff }}},
$$

where $E_{\mathrm{p}}$ is the pulse energy, $A_{\text {eff }}$ is the effective mode area at the $1 / \mathrm{e}^{2}$ intensity level.

All the saturable absorbers used in this study had a high modulation depth $\Delta R$ in the range of $22-37 \%$. In contrast, SESAMs for solid-state lasers have the modulation depth in the range of $1-2 \%$. The typical carrier recombination time for a bulk semiconductor material is hundreds of picoseconds or even nanoseconds. For a stable operation of a fiber laser it should be reduced down to a few picoseconds by varying the growth temperature [14]. SESAMs with three different carrier relaxation times: 1 ps (type I), 15 ps (type II), and 7 ps (type III), were chosen for the degradation studies. To show the difference between resonant and anti-resonant SESAMs, the low-intensity spectral reflectance measurements were performed (see Fig. 2). Due to the cavity enhancement of the electrical field on the QW structure, a sharp decrease of reflectance at around $1050 \mathrm{~nm}$ wavelength was observed for a type-III SESAM which had a resonant structure. For type-I and type-II SESAMs, the reflectivity curve had a much broader minimum indicating an anti-resonant structure. The nonlinear reflectivity curves of all three SESAMs are presented in Fig. 3 .

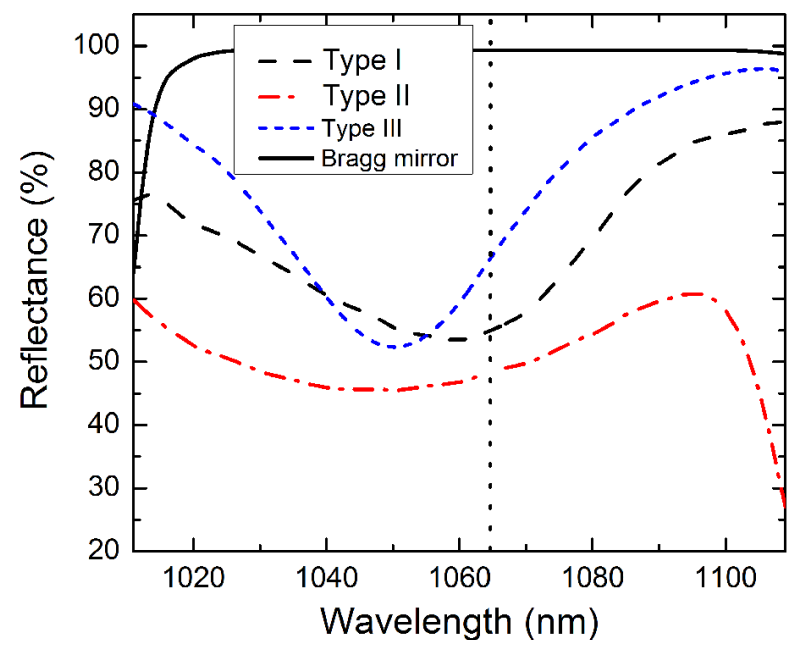

Fig. 2. Low intensity spectral reflectance of three different kinds of SESAMs used in this study. Measurements were performed on pigtailed chips of type-I, type-II, and type-III SESAMs. Dashed line indicates the theoretically calculated spectral reflectance of the Bragg mirror consisting of $25 \mathrm{AlAs} / \mathrm{GaAs}$ pairs and central wavelength at $1064 \mathrm{~nm}$.

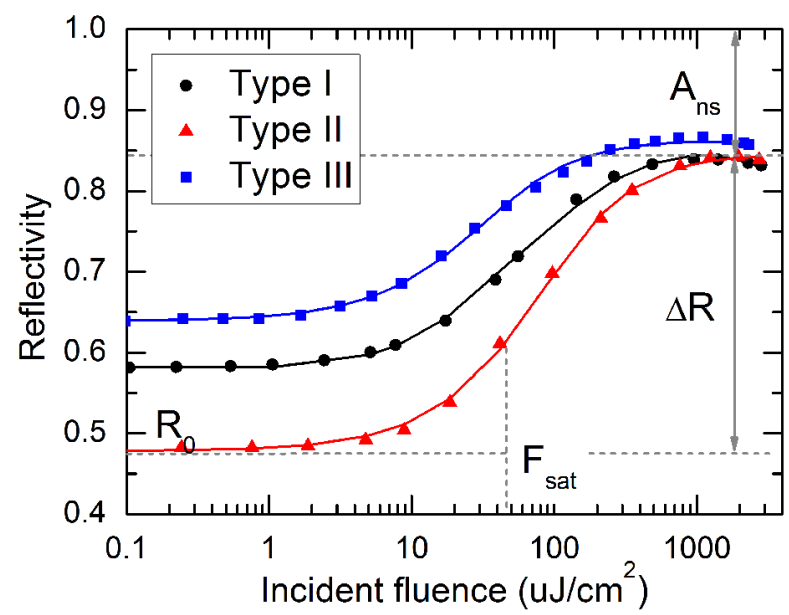

Fig. 3. Nonlinear reflectivity of three different kinds of SESAMs used in this study. Measurements were performed on pigtailed chips using picosecond pulses (1.6ps) from the fiber laser at $1064 \mathrm{~nm}$. For type-II SESAM derived parameters of nonlinear reflectivity are also presented: $R_{0}$ low intensity reflectivity, $\Delta R$ modulation depth, $A_{\text {ns }}$ non-saturable loss, $F_{\text {sat }}$ saturation fluence.

The static nonlinear response parameters of SESAMs were found by fitting the experimental data to Eq. (1). They are listed in Table along with carrier recombination times $\left(\tau_{\text {relax }}\right)$ provided by the manufacturer, which we did not verify.

Table. Parameters of nonlinear response of different types of SESAMs used in the study.

\begin{tabular}{c|c|c|c|c}
\hline SESAM & $F_{\text {sat' }} \mu \mathrm{J} / \mathrm{cm}^{2}$ & $\Delta R, \%$ & $A_{\mathrm{ns}^{\prime}} \%$ & $\begin{array}{c}\tau_{\text {relax }} \mathrm{ps} \\
(\text { specified })\end{array}$ \\
\hline Type I & 35 & 27 & 15 & 1 \\
\hline Type II & 47 & 37 & 15 & 15 \\
\hline Type III & 20 & 22 & 13 & 7 \\
\hline
\end{tabular}

A figure of merit to describe the saturation level of the absorber is the saturation parameter $S$. It is defined as a ratio of the incident fluence to the saturation fluence of the SESAM:

$$
S=\frac{F_{\mathrm{p}}}{F_{\text {sat }}} .
$$

This parameter allows comparing the saturation level of SESAMs with different saturation fluencies as is the case in our study. During the exposure, the saturation fluence of the absorber is modified. Therefore, the saturation parameter also changes in time. To simplify the situation we refer to the initial saturation parameter. Usually, the SESAM mode-locked Yb-doped fiber lasers operate in the range of $S=10-30$ [19]. 
For degradation studies, reflectivity of the SESAM was monitored continuously by measuring reference and reflected power from the SESAM. It was assumed that degradation will lead to the reduction of reflectivity. The time-dependent degradation of normalized reflectivity was fitted using a single exponential function with the offset:

$$
R_{\mathrm{N}}(t)=1-d R \cdot \mathrm{e}^{-\frac{t}{\tau}}
$$

where $d R$ is the total drop of reflectivity (at $t>>\tau), \tau$ is the decay time, during which $63 \%(1-1 / \mathrm{e})$ of the total drop of reflectivity occurred.

Because in all the cases the reflectivity was measured at high saturation levels, decrease of reflectivity was directly related to the increase of non-saturable loses of the SESAM:

$$
A_{\mathrm{ns}}=1-R \text {, when } S>>1 \text {. }
$$

After the experiment, a nonlinear reflectivity curve was measured again and compared to the initial curve to see how other parameters $\left(R_{0}, F_{\text {sat }}, \Delta R\right)$ have been changed.

\section{Experiment}

\subsection{Slow degradation set-up}

Ultrashort optical pulses were produced from a SESAM mode-locked all-in-fiber picosecond oscillator working at the $1064 \mathrm{~nm}$ central wavelength (Fig. 4). The chirped fiber Bragg grating was used as an end mirror for the wavelength stabilisation and dispersion compensation in order to achieve the picosecond pulse duration. A SESAM chip was butt-coupled to a FC/ PC optical fiber ferrule and worked as the second end-mirror forming a linear resonator. We used the ytterbium-doped polarization-maintaining singlemode fiber (YDF) as an active medium. This fiber was directly pumped by a laser diode with the central wavelength of $976 \mathrm{~nm}$. The micro-optical fiber pigtailed beam splitter was spliced in between YDF and SESAM. It provided two output ports - one for the light directed to the SESAM and another for the reflected pulses. The splitter also doubled as a polarizer in the resonator. The oscillator could generate nearly the bandwidth-limited pulses with the duration of $\sim 3$ ps at the repetition rate of $30-50 \mathrm{MHz}$ depending on the total fiber length in the resonator. The average output power was in the range of $\sim 3-10 \mathrm{~mW}$. Even at this low average power, the incident intensity on the SESAM was on the order of a few $100 \mathrm{MW} / \mathrm{cm}^{2}$ due to a short pulse duration and small mode area of the fiber.

Four SESAM chips were investigated in the slow degradation set-up: one with 1 ps relaxation time (type I) and three with 15 ps relaxation time (type II). The saturation parameter was in the range of $S=25$ 34. The repetition rate of the oscillators was $54 \mathrm{MHz}$ for type-I and $54 \mathrm{MHz}, 46 \mathrm{MHz}$, and $31 \mathrm{MHz}$ for type-II SESAMs. Power from two output ports of the fiber laser was measured with a Si photodiode power sensor every two-three days. During the test the

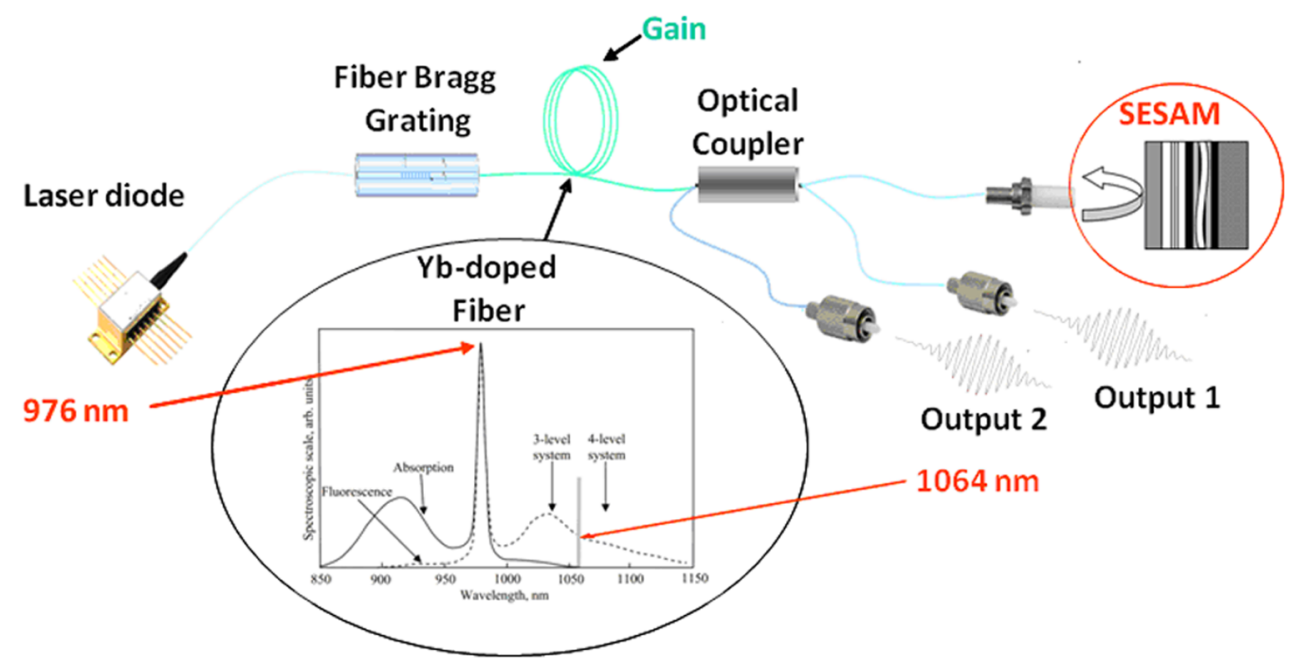

Fig. 4. Principal optical scheme of the picosecond fiber oscillator used in this study with main components marked. At the bottom are absorption and emission spectra of the $\mathrm{Yb}$ doped fiber [20]. Position in the spectrum of the pump wavelength $(976 \mathrm{~nm})$ and of output wavelength $(1064 \mathrm{~nm})$ is shown with the arrows. 
pump current was increased slightly for a couple of times to make sure the laser is well above the modelocking threshold. Simultaneously up to four separate fiber lasers could be operated.

\subsection{Fast degradation set-up}

For the investigation of degradation under a high saturation level, SESAMs were exposed to the laser radiation from the amplified fiber oscillator. The incident power on the SESAM could be controlled with a fiber-based attenuator connected before the SESAM. The maximum power achievable in this set-up was $\sim 30 \mathrm{~mW}$ with the optical pulse duration of $1.6 \mathrm{ps}$ and the repetition rate of $34 \mathrm{MHz}$. At these conditions, $2.8 \mathrm{~mJ} / \mathrm{cm}^{2}$ fluence could be reached on the SESAM with corresponding intensity of $2 \mathrm{GW} / \mathrm{cm}^{2}$. Even with the highest available fluence on type-I and type-II SESAMs there was a little degradation during the $24 \mathrm{~h}$ period. Therefore, it was not practical to carry out the fast degradation tests of these SESAMs. Instead, the resonant type-III SESAMs which have a lower saturation fluence due to the cavity enhancement of the electrical field on the QW structure were used. This allowed reaching the higher saturation parameter with the same available power and to observe degradation in a shorter time period. The nonlinear reflectivity measurements of SESAMs were performed before and after the fast degradation experiment as in the case of the slow degradation experiment. The saturation parameter was varied in the range of $S=73-$ 118 in these experiments.

\section{Results and discussion}

\subsection{Slow degradation results}

The main results of the slow optical degradation of type-I $\left(\tau_{\text {relax }}=1 \mathrm{ps}\right)$ and type-II $\left(\tau_{\text {relax }}=15 \mathrm{ps}\right)$ SESAMs are shown in Fig. 5. Curve (1) in Fig. 5 represents the long-term investigation of in situ reflectivity of the type-I SESAM with the initial saturation parameter $S_{1}=34$. The pulse repetition rate of this oscillator was $v_{1}=54 \mathrm{MHz}$. The oscillator stopped mode-locking at $1060 \mathrm{~h}$ after the beginning of the experiment. This is very close to the decay time $\tau_{1}=1000 \mathrm{~h}$ derived from the exponential fit of the reflectivity change (see Eq. (4)). From the same fit, the total drop of reflectivity of the type-I SESAM was predicted to be $d R_{1} \sim 40 \%$ at these conditions. Due to the limited availability of pump power the laser stopped mode-locking when reflectivity decreased by $27 \%$ from the initial reflectivity.

Three type-II SESAMs were also investigated at similar conditions (see curves (2),(3), and (4) in

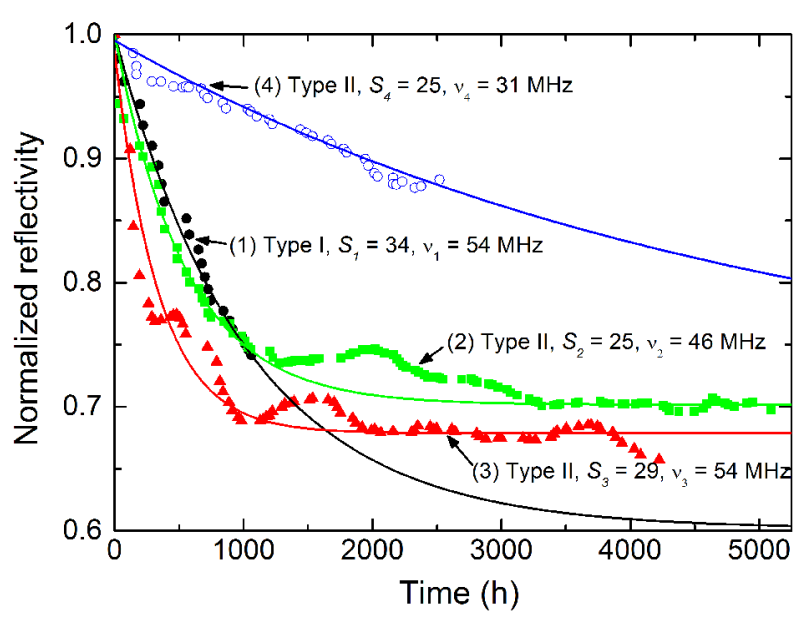

Fig. 5. Slow degradation of in-situ reflectivity (normalised to 1 at the start) of type-I and type-II SESAMs. The experimental data is the running monthly average to reduce the noise due to random fluctuations of the laser power. Exponential decay fits described in Eq. (4) are presented along the data. The decay time $\tau$ obtained from the fits was: (1) $1000 \mathrm{~h}$, (2) 550, (3) $340 \mathrm{~h}$, (4) $5000 \mathrm{~h}$.

Fig. 5). The chip with $S_{2}=25$ and $v_{2}=46 \mathrm{MHz}$ had a fitted decay time of only $\tau_{2}=550 \mathrm{~h}$ and the total drop of reflectivity of $d R_{2} \sim 30 \%$, but, in this case the fiber oscillator maintained the state of the self-starting mode-locking for more than $5000 \mathrm{~h}$ and is still operational at the moment of writing the paper. Another type-II SESAM was subjected to the saturation level of $S_{3}=29$ and the repetition rate of the incident pulses of $v_{3}=54 \mathrm{MHz}$ to have a more direct comparison to the type-I SESAM test. The degradation curve was fitted with the exponential function with the decay time $\tau_{3}=340 \mathrm{~h}$ and $d R_{3}=32 \%$, but again the laser maintained the state of self-starting mode-locking even after $4000 \mathrm{~h}$ of operation.

There seems to be a major difference in the degradation dynamics of the "fast" (1 ps, type I) and "slow" (15 ps, type II) SESAMs. Firstly, the speed of the initial decrease of the reflectivity is higher for type-II SESAMs, even at a lower saturation level. However, the most surprising difference is the ability of the "slow" SESAM to maintain the self-starting modelocking even after the initial decay has saturated. It also indicates that the reflectivity measurements do not tell a whole story, and any modification of other parameters, especially the saturation fluence and relaxation time, can also play a major role in the useful lifetime of the SESAM as a mode-locking device. These parameters are more difficult to measure insitu (inside the laser resonator) and it was out of the scope of this study to track all the parameters of the 
nonlinear reflectivity in time. However, we performed the nonlinear reflectivity measurement of SESAMs before and after the degradation experiments. The results for the type-II SESAM $\left(S_{2}=25\right.$ and $\left.v_{2}=46 \mathrm{MHz}\right)$ are shown in Fig. 6. Similar behaviour was also observed for other tested samples in the slow degradation study. The modulation depth $\Delta R$ for this particular SESAM decreased from $37 \%$ to $14 \%$. From our experience this is a lower limit for the self-starting mode-lock operation for this laser configuration, indicating that the laser is close to the end of its useful lifetime. The low-intensity reflectivity $R_{0}$ decreased moderately from $49 \%$ to $36 \%$ and saturation fluence $F_{\text {sat }}$ increased from 45 to $230 \mu \mathrm{J} / \mathrm{cm}^{2}$. The largest change was observed for the coefficient of the inverse saturable absorption (ISA) $F_{\text {ISA }}$ which decreased from 700 to $38 \mathrm{~mJ} / \mathrm{cm}^{2}$ indicating that a very strong limiting process was induced by the optical damage which reduced the reflectivity at the high incident fluence. The origin of this process is not clear. There are two main mechanisms for ISA - the two-photon absorption in GaAs spacers and the excited-state absorption in InGaAs QWs [18]. The peak intensity of the pulses in these experiments was relatively modest $\left(<1 \mathrm{GW} / \mathrm{cm}^{2}\right)$, and therefore only a little contribution

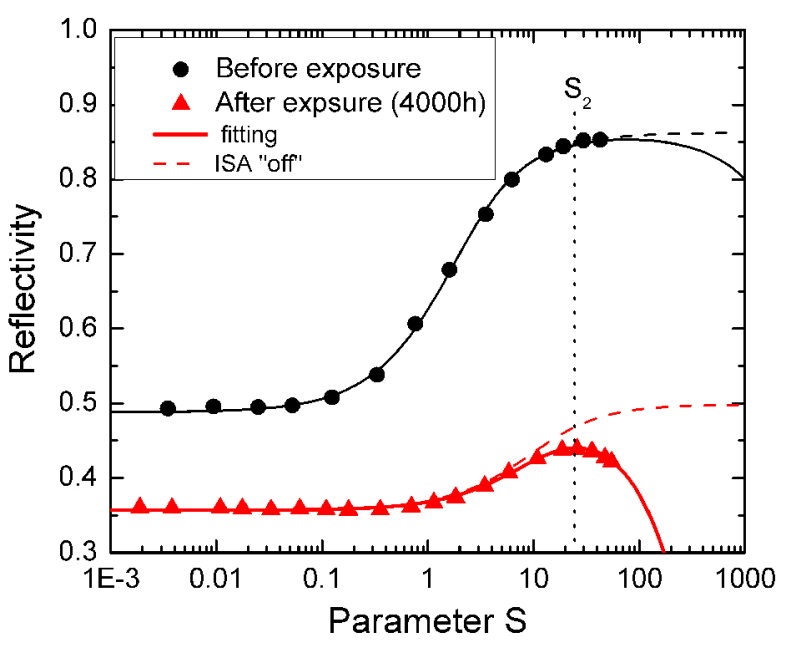

Fig. 6. Results of nonlinear reflectivity measurement of the type-II SESAM before (circles) and after (triangles) $4000 \mathrm{~h}$ of the slow optical degradation test at the saturation level of $S_{2}=25$ and repetition rate of $v_{2}=46 \mathrm{MHz}$. Fitting curves (solid lines) and fitting curves with ISA "turned off" (dashed lines) are also shown. For the reflectivity measurements after degradation, $x$-scale is normalized relative to the saturation fluence of a "fresh" SESAM $\left(45 \mu \mathrm{J} / \mathrm{cm}^{2}\right)$. The parameters obtained from the fittings are: $R_{0}=49 \%, \Delta R=37 \%, F_{\text {sat }}=45 \mu \mathrm{J} / \mathrm{cm}^{2}$, $F_{\text {ISA }}=700 \mathrm{~mJ} / \mathrm{cm}^{2}$ before degradation and $R_{0}=36 \%$, $\Delta R=14 \%, F_{\text {sat }}=230 \mu \mathrm{J} / \mathrm{cm}^{2}, F_{\text {ISA }}=38 \mathrm{~mJ} / \mathrm{cm}^{2}$ after degradation. to the total absorption from the two-photon absorption in $\mathrm{GaAs}$ is expected. On the other hand, almost three-fold reduction of $\Delta R$ indicates that the InGaAs QW structure is heavily modified. Therefore, it can be tentatively assumed that the increase of ISA is due to some defects created in the InGaAs quantum wells.

Additionally, the slow degradation study was performed on the type-II SESAM with the saturation parameter of $S_{4}=25$ and the repetition rate $v_{4}=31 \mathrm{MHz}$ (Fig. 5, curve (4)). Due to a later start of this experiment, the laser was operating for "only" about $2500 \mathrm{~h}$ at the time of writing. After this time, a relative decrease of reflectivity $d R_{4}$ was $\sim 12 \%$ compared to $\sim 30 \%$ for the second sample $\left(S_{2}=25\right.$ and $\left.v_{2}=46 \mathrm{MHz}\right)$. Even a more remarkable exponential decay time was found $\tau_{4} \sim 5000 \mathrm{~h}$ which is roughly ten times more than $\tau_{2}=550 \mathrm{~h}$. However, the total drop of reflectivity was fitted to be the same as for the second sample, $d R_{4} \sim 30 \%$. If we assume the behaviour of the SESAM at these conditions to be similar to other type-II SESAMs, the expected lifetime in this configuration should also be about ten times longer than the decay time or approximately $50000 \mathrm{~h}$ ! Such a large increase in the decay time is hard to explain by 1.5 times lower pulse repetition rate on the SESAM. This observation indicates that thermal effects may play a major role in degradation of the absorber. Thermal effects on the lifetime of SESAMs will be studied in more detail in the future.

\subsection{Fast degradation results}

Aiming to find a protocol for the accelerated lifetime measurements, we performed the fast degradation experiments at the high saturation parameter $S$ with type-III SESAMs. The time-dependent degradation of reflectivity at different $S$ values is shown in Fig. ․ ․ Initially, reflectivity decays exponentially, as in the case of the measurements at a lower saturation level. The decay time depends strongly on the saturation parameter. At the lowest saturation level of $S=73$, the decay time was found to be equal to $\tau=7.7 \mathrm{~h}$ (Fig. 7, curve (1)). It fell down to $\tau=0.6 \mathrm{~h}$ at the highest fluence corresponding to $S=118$ (Fig. 目, curve (5)). After the reflectivity decayed by $\sim 2 \%$ (lowest fluence) to $\sim 10 \%$ (highest fluence), all samples experienced the catastrophic optical damage (COD) observed as a sudden drop of reflectivity by $\sim 30 \%$ from the initial value independently of the fluence (see Fig. 7). When the experiment was repeated for several times, it was noticed that the time interval to COD was less reproducible compared to the decay time, but in general it decreased when the fluence was increased.

The nonlinear reflectivity measurements before exposure, after certain exposure time but before 


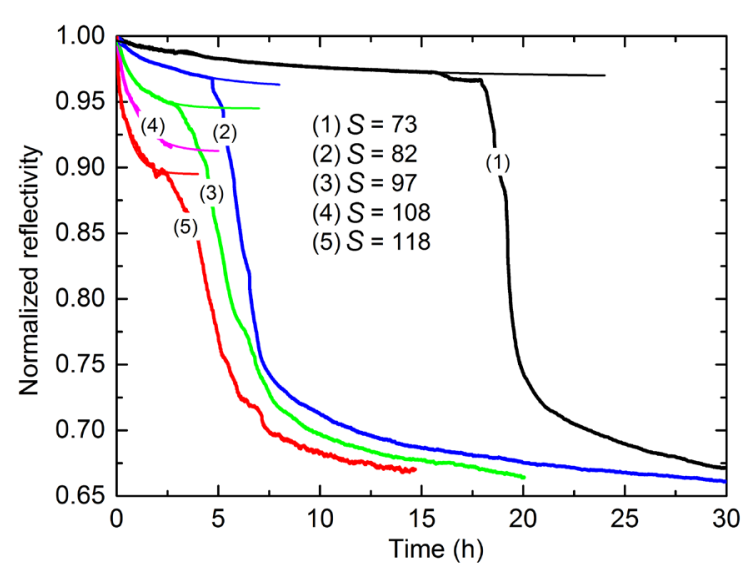

Fig. 7. Fast optical degradation of reflectivity (normalised) of the type-III SESAM at different values of the saturation parameter. Exponential decay fits described in Eq. (4) are presented along the data. Decay time $\tau$ obtained from the fits was: (1) $7 \mathrm{~h}$, (2) 3.1 , (3) $1.1 \mathrm{~h}$, (4) $1 \mathrm{~h}$, (5) $0.6 \mathrm{~h}$. Measurements at $S=108$ (curve (4)) were truncated due to limited time available for that particular experiment.

COD, and after COD were performed. The reflectivity curves are presented in Fig. 8 for the lowest incident fluence, but similar results were also obtained for other fluencies. As expected, the entire reflectivity curve after the exposure is below the initial curve; however,

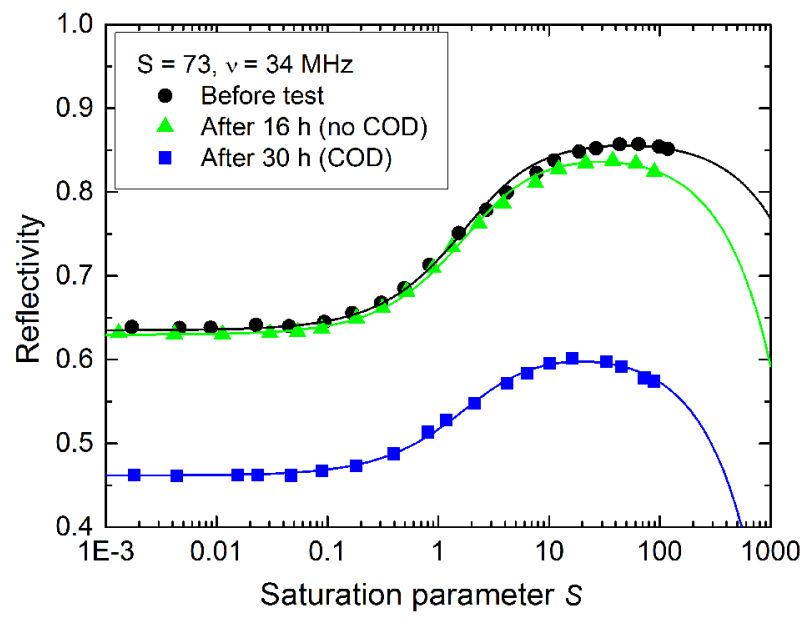

Fig. 8. Results of nonlinear reflectivity measurement of the type-III SESAM at the beginning of the fast degradation test (circles), after 15 hours of exposure (triangles), and after COD (squares) along with fitting curves (solid lines). The parameters derived from the fittings are: $R_{0}=63 \%, \Delta R=22 \%, F_{\text {sat }}=20 \mu \mathrm{J} / \mathrm{cm}^{2}, F_{\text {ISA }}=200 \mathrm{~mJ} /$ $\mathrm{cm}^{2}$ before exposure, $R_{0}=62 \%, \Delta R=22 \%, F_{\text {sat }}=21 \mu \mathrm{J} /$ $\mathrm{cm}^{2}, F_{\text {ISA }}=80 \mathrm{~mJ} / \mathrm{cm}^{2}$ after 15 hours of exposure, and $R_{0}=46 \%, \Delta R=15 \%, F_{\text {sat }}=27 \mu \mathrm{J} / \mathrm{cm}^{2}, F_{\text {ISA }}=70 \mathrm{~mJ} / \mathrm{cm}^{2}$ after 15 hours of exposure and COD. the character of the decrease of reflectivity is very different compared to the slow degradation study. From fitting the nonlinear reflectivity curves before and after exposure it was obtained that $R_{0}$ decreased from $63 \%$ to $46 \%$ after COD and $\Delta R$ decreased from $22 \%$ to $15 \%$. The relative modulation depth $\left(\Delta R / R_{0}\right)$ did not change significantly after COD (fell from 0.35 to 0.33 ). The saturation fluence slightly increased from 20 to $27 \mu \mathrm{J} / \mathrm{cm}^{2}$ and ISA coefficient measured after COD was reduced from $\sim 200$ to $70 \mathrm{~mJ} / \mathrm{cm}^{2}$. However, the majority of the decrease occurred in the phase of the exponential decay before COD when it reached $80 \mathrm{~mJ} / \mathrm{cm}^{2}$ (see Fig. 8 and the caption).

It is evident from these results that although the total decrease of reflectivity was similar in both low and high saturation conditions ( $30 \%)$, the processes leading to this degradation were entirely different in these two cases. To clarify this, we also took images of the damaged spots on the SESAMs after the tests. An image of the damaged area on the type-III SESAM after the fast degradation measurement and the endface image of the optical fiber used to pigtail the SESAM are shown in Fig. 9. The lighter affected area is encircled. A darker spot of the size of $\sim 2 \mu \mathrm{m}$ is visible in the centre of the affected area. This feature is present on the surface of SESAMs only after the fast degradation tests. Because the size of this feature is considerably larger than the mode-field diameter of the optical

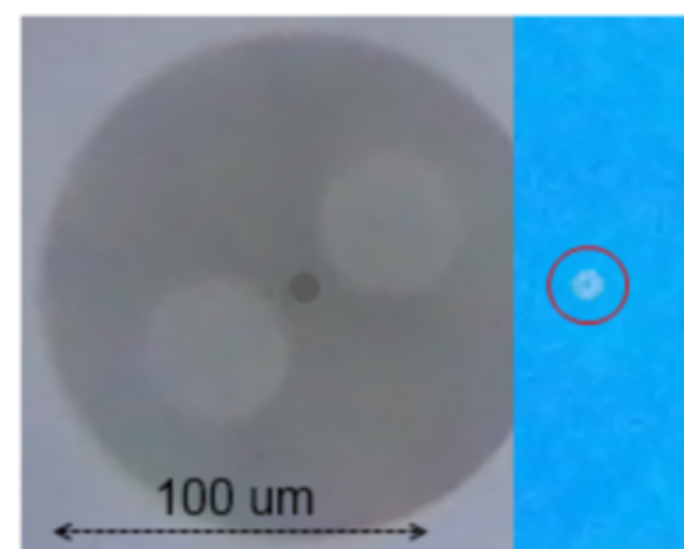

Fig. 9. On the left: Microscope image of a fiber end-face used to pigtail SESAMs. Stress rods are visible on both sides of the central part. The darker region at the centre is the optical core $(\sim 7 \mu \mathrm{m}$ in diameter) where the light propagates. On the right: Microscope image with the same magnification of the affected area (encircled) of the type-III SESAM after COD at the highest saturation level of $S=118$. The darker spot of $\sim 2 \mu \mathrm{m}$ is clearly visible at the centre of this area. 
fiber, it can be assumed that only the central part of the light field had enough intensity to create this defect. This is not really surprising, as the intensity at the central part of the mode is $\mathrm{e}^{2}$ times higher the intensity at the "edge" (distance from the centre equal to the mode field radius). If we assume that the damage is created by a nonlinear process, e. g. two-photon absorption in GaAs, the ratio of the absorbed photons at the centre and the edge will be $\left(I_{0} / I_{1 / \mathrm{e}}{ }^{2}\right)^{2}$ or $\mathrm{e}^{4} \approx 55$. This very sharp dependence on the position can be the reason for a very small size of the damage spot compared to the mode field diameter of the optical fiber. The small damage spot can also explain why the drop of the reflectivity of the SESAM is only $\sim 30 \%$ and not close to $100 \%$ as can be expected in the case of COD, as the area not affected by the direct damage can still perform as before COD.

To summarise, we performed, to our knowledge, the first systematic study of slow and fast degradation of SESAMs for the fiber laser mode-locking. The main findings were that the SESAMs with a slower (15 ps) carrier relaxation time showed a considerably longer lifetime $(>5000)$ in the mode-locked fiber laser compared to the SESAMs with a faster carrier relaxation (1 ps, $\sim 1000 \mathrm{~h})$. At a lower repetition rate and reduced thermal load, the expected lifetime is forecasted to be well above $10000 \mathrm{~h}$. The accelerated damage test revealed that the mechanism of degradation at higher saturation levels $(S=73-118)$ was different from that of slow degradation at lower saturation $(S=25-34)$. It was deduced that the optical damage of the GaAs material probably by the two-photon absorption was the mechanism of the critical optical damage at the high fluence, and the degradation of the InGaAs quantum well structure was the most likely reason for the slow degradation at the lower fluence.

\section{Acknowledgements}

This research was funded by the European Social Fund, Project No. VP1-3.1-ŠMM-10-V-02-002.

\section{References}

[1] A.H. Zewail, Femtochemistry: atomic-scale dynamics of chemical bond. J. Phys. Chem. A 104, 5660-5694 (2000), http://dx.doi.org/10.1021 ip001460h

[2] A. Stolow, A.E. Bragg, and D.M. Neumark, Femtosecond time-resolved photoelectron spectroscopy, Chem Rev. 104(4), 1719-1758 (2004), http:// dx.doi.org/10.1021/cr020683w

[3] J. Adamonis, N. Rusteika, R. Danilevičius, and A. Krotkus, A compact terahertz burst emission system driven with $1 \mu \mathrm{m}$ fiber laser, Opt. Commun.
293, 61-64 (2013), http://dx.doi.org/10.1016/j. optcom.2012.11.100

[4] M.E. Fermann, A. Galvanauskas, and G. Sucha, Ultrafast Lasers: Technology and Applications (Marcel Dekker, New York, 2003), http://www.crcnetbase.com/isbn/9780203910207

[5] H. Endert, A. Galvanauskas, G. Sucha, R. Patel, and M. Stockin, Novel ultrashort pulse fiber lasers for micromachining applications, RIKEN Rev. 43, 23-27 (2002), http://citeseerx.ist.psu. edu/viewdoc/download?rep=rep 1\&type $=$ pdf\&d oi=10.1.1.222.9515

[6] G. Račiukaitis, S. Grubinskas, P. Gečys, and M. Gedvilas, Selectiveness of laser processing due to energy coupling localization: case of thin film solar cell scribing, Appl. Phys. A 112 (1), 93-98 (2012), http://dx.doi.org/10.1007/s00339-012-7206-x

[7] O. Okhotnikov, A. Grudinin, and M. Pessa, Ultra-fast fiber laser systems based on SESAM technology: new horizons and applications, New J. Phys. 6(177), 1-22 (2004), http://dx.doi. org/10.1088/1367-2630/6/1/177

[8] A.M. Heidt, J.P. Burger, J.-N. Maran, and N. Traynor, High power and high energy ultrashort pulse generation with a frequency shifted feedback fiber laser, Opt. Express 15(24), 15892 (2007), http:// dx.doi.org/10.1364/OE.15.015892

[9] G. Steinmeyer, D.H. Sutter, L. Gallmann, N. Matuschek, and U. Keller, Generation: pushing the limits in linear and non-linear optics, Science 286(5444), 1507-1512 (1999), http://dx.doi. org/10.1126/science.286.5444.1507

[10] R.J. Collins and P. Kisliuk, Control of population inversion in pulsed optical masers by feedback modulation, I. Appl. Phys. 33, 378-388 (1962), http://dx.doi.org/10.1063/1.1728883

[11] F.W. Wise, A. Chong, and W.H. Renninger, Highenergy femtosecond fiber lasers based on pulse propagation at normal dispersion, Laser Photon. 2(1-2), 58-73 (2008), http://dx.doi.org/10.1002/ lpor.200710041

[12] A. Chong, J. Buckley, W. Renninger, and F. Wise, All-normal-dispersion femtosecond fiber laser, Opt. Express 14(21), 10095-10100 (2006), http:// dx.doi.org/10.1364/OE.14.010095

[13] A. Ruehl, D. Wandt, U. Morgner, and D. Kracht, On wave-breaking free fiber lasers mode-locked with two saturable absorber mechanisms, Opt. Express 16(11), 8181-8189 (2008), http://dx.doi. org/10.1364/OE.16.008181

[14] U. Keller et al., Semiconductor saturable absorber mirrors (SESAMs) for femtosecond to nanosecond pulse generation in solid-state lasers, IEEE J. Sel. Top. Quant. Electron. 2, 435 (1996), http:// dx.doi.org/10.1109/2944.571743

[15] S. Kivistö, T. Hakulinen, A. Kaskela, B. Aitchison, D.P. Brown, A.G. Nasibulin, E.I. Kauppinen, A. Härkönen, and O.G. Okhotnikov, Carbon 
nanotube films for ultrafast broadband technology, Opt. Express 17(4), 2358-2363 (2009), http://dx.doi.org/10.1364/OE.17.002358

[16] Z. Sun, T. Hasan, F. Torrisi, D. Popa, G. Privitera, F. Wang, F. Bonaccorso, D.M. Basko, and A.C. Ferrari, Graphene mode-locked ultrafast laser, ACS Nano 4(2), 803-810 (2010), http://dx.doi. org/10.1021/nn901703e

[17]F.G. Celii, L.A. Files-Sesler, E.A. Beam, and H.-Y. Liu, In situ detection of InGaAs strainedlayer relaxation by laser light scattering, J. Vac. Sci. Technol. A 11, 1796 (1993), http://dx.doi. org/10.1116/1.578428

[18]C.J. Saraceno, C. Schriber, M. Mangold, M. Hoffmann, O.H. Heckl, C.R.E. Baer, M. Golling, T. Ud- meyer, and U. Keller, SESAMs for high-power oscillators: Design guidelines and damage thresholds, IEEE J. Sel. Top. Quant. Electron. 18, 29-41 (2012), http://dx.doi.org/10.1109/JSTQE.2010.2092753

[19] R. Herda and O.G. Okhotnikov, Dispersion compensation-free fiber laser mode-locked and stabilized by high-contrast saturable absorber mirror, IEEE J. Quant. Electron. 40(7), 893-899 (2004), http://dx.doi.org/10.1109/JQE.2004.830194

[20] H.M. Pask, R.J. Carman, D.C. Hanna, A.C. Tropper, C.J. Mackechnie, P.R. Barber, and J.M. Dawes, Ytterbium-doped silica fiber lasers: versatile sources for the 1-1.2 $\mu \mathrm{m}$ region, IEEE J. Sel. Top. Quant. Electron. 1, 2-13 (1995), http://dx.doi. org/10.1109/2944.468377

\title{
SKAIDULINIŲ LAZERIŲ MODŲ SINCHRONIZACIJAI SKIRTŲ SESAM DARINIUU LĖTA IR SPARTI DEGRADACIJA ESANT $1 \mu \mathrm{m}$ BANGOS ILGIUI
}

\author{
K. Viskontas ${ }^{\text {a, }}$, K. Regelskis ${ }^{\text {a, }}$, N. Rusteika ${ }^{\text {a, b }}$ \\ a Fiziniu ir technologijos mokslu centras, Vilnius, Lietuva

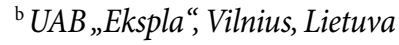

\section{Santrauka}

Darbe pristatytas $\operatorname{In}_{x} \mathrm{Ga}_{1-x}$ As kvantinių duobių pagrindu pagamintų puslaidininkinių issisotinančios sugèrties veidrodžių (SESAM), apšviestų pikosekundiniais skaidulinio $1064 \mathrm{~nm}$ osciliatoriaus impulsais, degradacijos tyrimas. Ilgalaikių degradacijų tyrime, kuris atliktas su mažesniais impulsų energijos tankiais, du ilgiausiai veikę lètos relaksacijos ( $\tau=15$ ps) SESAM pasiekè $\sim 4000 \mathrm{~h}$, o greitos relaksacijos ( $\tau=1 \mathrm{ps}$ ) SESAM tik 1000 h. Netiesinio atspindžio matavimai rodo,
\end{abstract}

kad InGaAs kvantinių duobių optinè modifikacija yra pagrindine SESAM degradacijos priežastis. Be to, sumažinus termini poveiki, SESAM tikètina gyvavimo trukmè padidejo dešimt kartų. Prie didesnių energijos tankių stebimas staigus SESAM pažeidimas, po ijungimo praejjus mažiau nei 24 valandoms. Toks pažeidimas siejamas su dvifotone sugertimi GaAs sluoksnyje. Dèl skirtingu SESAM degradacijos mechanizmų pademonstruota būtinybè atlikti ilgalaikius testus realaus skaidulinio lazerio veikimo sąlygomis. 